\title{
Enhancing the resilience of levee systems through methodological developments
}

\author{
Marc Igigabel ${ }^{1, a}$, Youssef Diab², and Marissa Yates ${ }^{3}$ \\ ${ }^{1}$ Cerema, Technopôle Brest Iroise, 155 rue pierre Bouguer, BP5, 29280 Plouzané, France \\ 2 Université Gustave Eiffel, Lab'Urba, 5, Boulevard Descartes, 77430 Champs sur Marne \\ ${ }^{3}$ Saint-Venant Hydraulics Laboratory \& Cerema, 6 quai Watier, BP 49, 78401 Chatou, France
}

\begin{abstract}
The resilience of levee systems is intuitively associated with physical and technical measures applied to aide in the recovery or adaptation after a destructive event. However, facing a hazard whose characteristics are never fully anticipated and to which a fully predetermined response cannot be proposed, the responsiveness of levee managers depends primarily on their ability to make decisions that must necessarily be based on a sufficient level of information and be supported by appropriate methodological frameworks. Building on previous research about the response to the Xynthia storm, this paper demonstrates that the resilience of protection systems involves expanding the approaches for hazard characterization, flood protection system definition, and intervention modes. With climate change, and the current ecological and digital transitions, methodological developments in the field of flood protection should also encourage the mobilization of more varied disciplines and strengthen solidarity between stakeholders. These links must be woven in the long term, under normal conditions, to be put in place rapidly in emergency situations. Ultimately, methodologies and operational tools must be developed for all (both normal and emergency) circumstances, within the framework of a global, integrated and cohesive approach.
\end{abstract}




\section{INTRODUCTION}

Levee managers are confronted with a double problem:

- to maintain levee systems with limited material and human resources, to maintain its performance;

- to adapt the levee system in response to crisis situations or to changes in society and the environment.

The fact that we inherit, generation after generation, even over centuries, the management of levees, naturally leads us to consider primarily the first point, which can result in conservative attitudes, resistance to change, and mainly technical approaches; methodological guides are then considered only as a form of support for the activity.

Yet in the 21st century, with major disturbances in our environment and profound transformations in society, adaptation should prevail over resistance. Under these conditions, additional effort should be made to define adaptation strategies, without lowering the standards in maintaining levels of protection...

In response to current and future trends, this article seeks to define methodologies, which are the backbone of decision-making schemes, that can contribute to the development of better protection against flood risk, either for adaptation or conservation purposes. These reflections make use of the last two decades of major advances in flood risk management and are demonstrated using the example of research relating to the Xynthia storm $(2010)^{1}$.

The article proceeds in two stages.

First, the concepts and strategies that have emerged over the past decades are explored, including those related to resilience, and how methodologies can integrate them to maintain or improve protection.

Second, and in a complementary way, the changes in the methodological procedures are evaluated, in particular with regard to:

- climate change impacts on the biophysical environment;

- more natural intervention modes (related to the ecological transition);

- observation, analysis, and modelling techniques that generate or use ever more diverse data (related to the digital transition).

Through analysis of levee systems, this paper aims to identify ways of developing resilience through a revision of the methodological procedures specifying their design

\footnotetext{
${ }^{1}$ Over the past 10 years, the feedback of this emblematic event

${ }^{1}$ Over the past 10 years, the feedback of this emblematic event
contributed significantly to the evolution of protection strategies in France.
}

a Corresponding author: marc.igigabel@cerema.fr DOI $10.3311 / \mathrm{xxx}$ and management, to seek a new balance with the natural environment and a transformation of our way of working.

\section{STUDY ORIENTATION}

Helping to strengthen the resilience of levee systems through methodological developments requires a clear definition of "resilience". This is not simply to clarify a vague definition, nor yet another attempt to propose an ideal definition for resilience applied to flood risk (Rodina [18] identifies 149 articles published between 1982 and 2017 dealing with this topic), but as a necessity for the remainder of this study. The goal is not to propose a new concept, but to work towards improving its application, by both identifying the most appropriate definition and finding ways of making the best use of it.

In addition, to enrich these reflections, an overview of operational strategies related to this concept will be provided, considering two perspectives:

(1) flood risk management (an extended point of view compared to our focal point targeting only protection systems); and

(2) the resilience of the urban environment to a variety of hazards (to further expand the range of possible strategies).

These operational strategies and their conceptual basis will be useful for defining the orientations of the study and analyzing the subject: strengthening levee system resilience through methodological developments.

\subsection{Definition of resilience}

The concept of resilience, originally used in physics to designate the energy absorbed by a body during a deformation, has been developed in many disciplines (such as psychology or ecology). In the field of flood risk, many authors have also employed this term, which has led to multiple variants of the definition. Here it is necessary to retain one definition. For this, two selection criteria are applied. The definition must:

- concern a "system", both in the general sense of a "set of interdependent elements that form an isolable whole" and in the practical sense of a "set of material, technical and strategic means aimed at achieving an objective". These two senses, defined in the online philosophical dictionary Dicophilo [7], apply to levee systems; and

- illuminate the multiple facets of the concept and open a wide range of possibilities for protection strategies.

Within the field of climate change adaptation, as discussed in this study, the Intergovernmental Panel on Climate Change (IPCC) defines resilience as:

"the ability of a system and its component parts to anticipate, absorb, accommodate, or recover from the effects of a hazardous event in a timely and efficient 
manner, including through ensuring the preservation, restoration, or improvement of its essential basic structures and functions" [14].

This definition fulfils the two conditions described above. It also has a consensual character by construction. Thus, it is retained for the remainder of this work.

\subsection{Utilization of the concept of resilience}

According to the chosen definition, resilience results from several modes of action, assured at the level of a system and its components: "anticipate, absorb, accommodate, or recover". In carrying out these functions, the importance of temporality and efficiency is highlighted. Since the aim of levee systems is to provide better protection, the development of these capacities corresponds to the same goal, and therefore methodological ways of achieving this must be identified. The definition also suggests moving in this direction through "the preservation, restoration, or improvement of its essential basic structures and functions".

"Preservation" and "restoration" contribute to a common objective of stability. In the field of engineering, this objective is achieved:

- first, by structural strength: the objective is achieved if the structures resist deterioration;

- $\quad$ second, when structures have been damaged, by their ability to be repaired, by natural or human actions.

Nevertheless, the search for stability is only meaningful when the evolution of the system occurs slowly. Conversely, with changes in hazards or issues, this objective of preservation or restoration is no longer sufficient and may even be inappropriate: for example, levees that retain water at heights that they were not initially designed for, may lead to increased risk.

The third objective identified in the definition of the IPCC, "improvement", differs from the previous two objectives because it corresponds to the capacity of adaptation. During and after each event, the system can be transformed to protect against dangerous effects with new characteristics. This is particularly valuable in a changing environment such as that caused by climate change. This ability to adapt appears less often in the field of engineering, which may idealize the design of systems and the permanency of their construction (in the form of civil engineering works, with the predominant use of concrete and steel). Conversely, this capacity is more regularly observed in the "living" fields of ecology and sociology.

The IPCC definition is particularly valuable in addressing this problem because it establishes the relationship between a hazard, "the effects of a dangerous event", and an object, "the system", providing guidance for the "modes of reaction" of the object to the hazard. This definition therefore already implies methodological developments: by specifying each of its terms (in a specific context), the essential references for decisionmaking are outlined. However, when applying this approach, the order in which the terms are defined is of great importance. In particular, one must avoid focusing first on modes of action, ignoring the knowledge of the hazard and the identification of the protection system. In the field of risk management, the willingness to act may in fact unconsciously limit the time devoted to acquiring knowledge. Thus, one is reminded that resilience development strategies can be defined only with sufficient knowledge of the hazard and of the object subjected to this hazard.

\subsection{Flood resilience development strategies}

Flood risk management strategies typically include protection measures (to reduce as much as possible the experienced risk) and measures to increase the resilience to the residual risk. In [8], the author explores the relationship between these two complementary approaches:

- flood risk assessment and implementation of appropriate protective measures limiting damage; and

- reinforcement of resilience, or the development of the ability to absorb the consequences of a flood.

Flood risk prevention policies have been developed based directly on the concept of resilience, with particular emphasis on protective measures. For example, as of 2009 in the Netherlands, the Four Capacities approach of [10] is based on:

- the threshold capacity (ability to resist floods);

- the coping capacity (ability to reduce damage from floods that exceed the damage threshold);

- the recovery capacity (ability to recover from losses after an event);

- and the adaptive capacity (ability to apply a wide range of adaptive measures).

In this approach, the four capacities reproduce nearly word for word the "anticipate, absorb, accommodate, or recover" phrase of the IPCC definition. Only the first capacity differs with its goal to provide protection up to a certain threshold. (In this approach, anticipation can be represented on the four axes.)

This approach reflects the fact that beyond the physical consequences of a large-scale extreme natural event, it is necessary to take into account:

- the social impact on the population: isolated people or people who can no longer access certain essential services, deterioration of health conditions, psychological distress; and

- the economic impact: cost of infrastructure restoration, loss of business income, including farms.

Under these conditions, it is clear that building resilience requires more comprehensive, qualitative 
approaches, involving more scientific disciplines, with ecology and social and economic sciences complementing engineering approaches. The definition of resilience depends on the object to which it applies, as well as the perspective that is taken (engineering, ecology, economy, etc.). Its assessment requires using indicators beyond performance indicators typically used in flood risk management (e.g. mapping of water heights against reference events, etc.). Since evaluation processes are essential for decision-making, methods have been developed to achieve this. To enrich our understanding of flood risk resilience, it is useful to provide an overview of such a method...

\subsection{Assessing the resilience of urban systems to diverse hazards}

The overall evaluation method, called the City Resilience Index, developed by Arup and the Rockefeller Foundation [1] under the 100 resilient cities program allows considering several hazards. Figure 1 provides a comprehensive view of the four dimensions to consider in building resilience: health and well-being, economy and society, infrastructure and ecosystems, governance and strategy. Each of these dimensions includes several goals (for a total of 12 goals), each of which may be evaluated according to several indices (for a total of 52 indices).

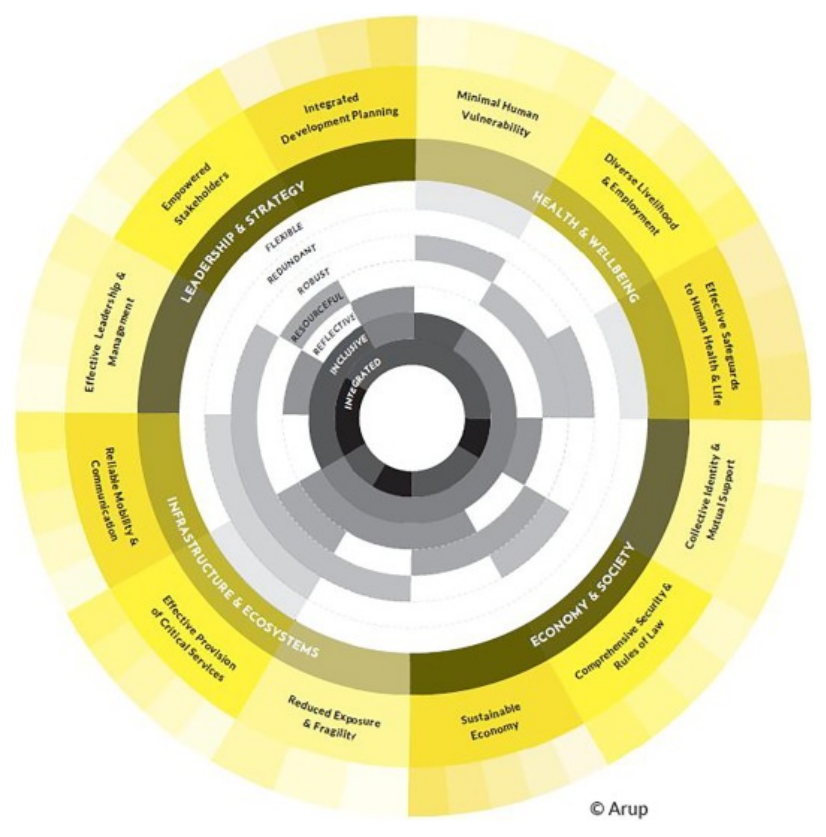

Figure 1. An example of the City Resilience Index [1], where the filled inner rings assess performance. The darkest color represents "very poor" and lightest color represents "excellent."

Considering levee systems stricto sensu (as opposed to a system that would integrate both the protection system and all the elements of the territory it protects or with which it interacts), the social and macro-economic views are not considered, and therefore the focus is on the last two dimensions: "infrastructure and ecosystems" and "leadership and strategy".
Each indice can be evaluated according to the qualitative resilience-enhancing attributes shown in Figure 2.

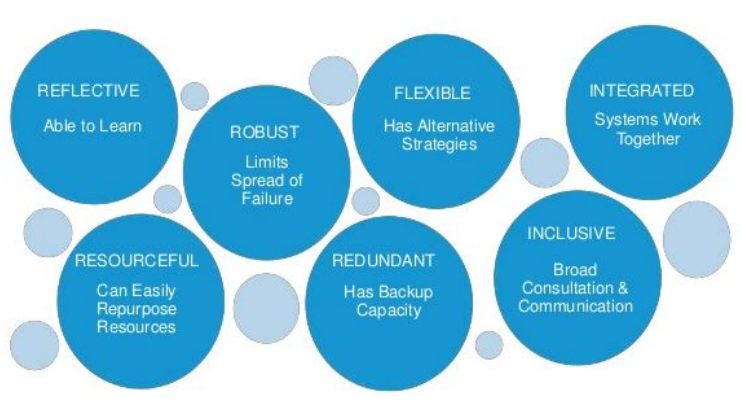

Figure 2. Qualitative attributes of a resilient system [1]

\subsection{Conclusion on the study orientation}

In order to explore the possibilities of strengthening the resilience of levee systems, methodological developments related to each term of the definition of resilience are examined using a sectoral approach, namely:

- the characterization of the hazard;

- the definition of the protection system; and

- the methods of preserving, restoring or improving the essential structures and functions of this system.

Secondly, through a unified approach, the opportunities to build resilience are explored by returning to methodological fundamentals and asking ourselves what mechanisms need to be implemented to strengthen their effectiveness given current and future global changes. As a follow-up to these considerations, adaptations in governance, expertise and planning are also sought. In accordance with the conclusions, this section is entitled "Seeking unity and consistency".

To illustrate this approach with an application, we will use marine flood protection systems as an example. The same thought process could also be adopted for other issues such as:

- a system designed to protect against other types of hazards; or

- a system that would integrate both the protection system, the vulnerable stakes and all the elements of the territory with which it interacts.

\section{SECTORAL METHODOLOGICAL DEVELOPMENTS}

Understanding the hazard and protection system requires a site-specific approach, in particular identifying the geographical, geological and hydraulic characteristics. It is generally observed by studying past events that the link between a protection system and a type of hazard should not be exclusive: for example, if only the coastal hydraulic phenomena are considered, the hazard may occur, in addition to overflowing and overtopping from the sea, by coastal river flooding, 
runoff, rising water levels... However, the flooding can also generate other phenomena: humid ground or powerful currents may cause mudslides, tree falls, cliff failures, cavity collapses or erosion impacting building foundations or local infrastructure... At the shoreline, marine flooding occurs during the passage of atmospheric depressions, which are often associated with high winds and waves breaking inland of tidal areas. To study the hazard implies first analyzing the different physical components and their possible combinations and sequences. The identification of the protection system and the actions required to ensure its preservation, restoration or improvement must be based in particular on this initial analysis.

\subsection{Characterisation of the hazard}

If coastal inundation alone is considered, the definition of the hazard can be relatively simple:

Coastal inundation occurs during storms that generate energetic sea states and increase the sea level.

Figure 3 shows the contributions to «static» and « instantaneous » water levels at the shoreline, as caused by meteorological and hydrodynamic phenomena.

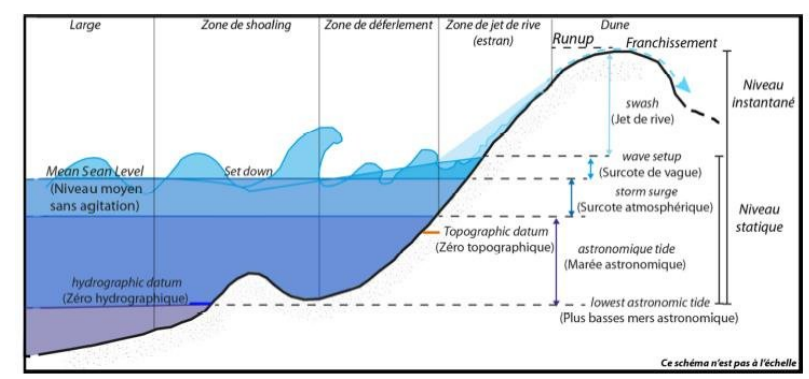

Figure 3. Forcings acting during a marine flood (Courtesy : Nicolae-Lerma)

For a case that is deliberately limited to a single type of hazard, however, the analysis reveals contrasting situations depending on the site, even regarding only the intensity and chronology of the events (these two parameters largely determine the level of danger):

- on tidal coasts, the most unfavorable case is the conjunction of the meteorological surge with the spring tide high water. The peak of the event has a maximum duration of about three hours, but overflows usually occur over an even shorter period around the high water level. Since these overflows can involve very long alongshore distances, water inflows can be very large;

- on coastlines not subject to large tidal variations - in France, the Mediterranean Coast - the rise of water is related only to the meteorological surge and wave breaking. This type of flooding event can last several days depending on the characteristics and duration of the storm.

- in hurricane-prone areas, meteorological and hydrodynamic phenomena may be of greater intensity, causing faster and larger-scale flooding. The duration of the event, from a few hours to several days, depends largely on the cyclone trajectory and kinetics, both of which are difficult to predict.

In all cases, breaches in levee systems are likely to deteriorate the situation by accelerating flows and increasing the volume of water entering the system by overflowing or overtopping of structures. Breaches also prolong the duration over which water inflows occur.

By reducing the analysis to a single hazard such as coastal flooding, the "combination of circumstances" is already daunting. For example, during the Xynthia storm, neither the intensity of the winds, nor the astronomical tide, nor the wave heights were exceptional. And yet, this storm, which was common from a strictly meteorological point of view, was exceptional by the conjunction of particular atmospheric and marine factors. Many sites on the French Atlantic coast were inundated, causing the death of 59 people and damages estimated at more than one billion euros. The poor condition of the protective structures, often neglected and without an identified manager, obviously also contributed to this tragedy.

As coastal flooding occurs during storm conditions, the combined effects of wind and marine currents are also difficult to understand when defining and implementing effective control measures. Some measures may thus be ineffective or even counterproductive. For example:

- the implementation of interventions on levees subject to water pressure may be hindered by intense wind gusts; or

- heavy equipment on water-saturated levees can cause settlement or instability.

\section{Potential methodological developments}

Hazards often result from a combination of phenomena, but also from particular land configurations or from unfortunate actions or activities. Research about hazards that focuses on developing statistical tools [17] is an appropriate response to assess the exceptional physical conditions (for example, in the case of marine flooding, water levels and wave heights) through the combination of several phenomena. However, in general these insights can only be provided at large spatial scales. They cannot take into account all of the local phenomena resulting from accumulation or cascade effects.

In the future, the objective of strengthening the resilience of systems could therefore involve methodological recommendations encouraging supplementing large-scale analyses with more local analyses taking into account a greater diversity of phenomena.

\subsection{Definition of the protection system}

At a given site, flood risk management is carried out by implementing a coherent set of measures to reduce the risk. These measures may be structural (for example, levee interventions or beach nourishments) or non- 
structural (for example, increasing population awareness or developing forecasting and alert tools). Considering only structural measures affecting the water propagation, a flood protection system can be defined as:

a set of structures or protective elements presenting an overall coherence from a hydraulic point of view to ensure the effective protection of a group of previously identified stakes.

The components of this system can be levees and other civil engineering works (breakwaters, groynes, seawalls, etc.), natural structures (beaches, dunes, shingle bars, etc.), as well as drainage, storage and evacuation systems. These latter devices, positioned inland, must not be neglected, as they ensure the water management, which must complement the defense measures protecting against water inflows (a system is always likely to have water inflows from the land or the sea). Figure 4 shows schematically how these elements can be positioned in a coastal zone.

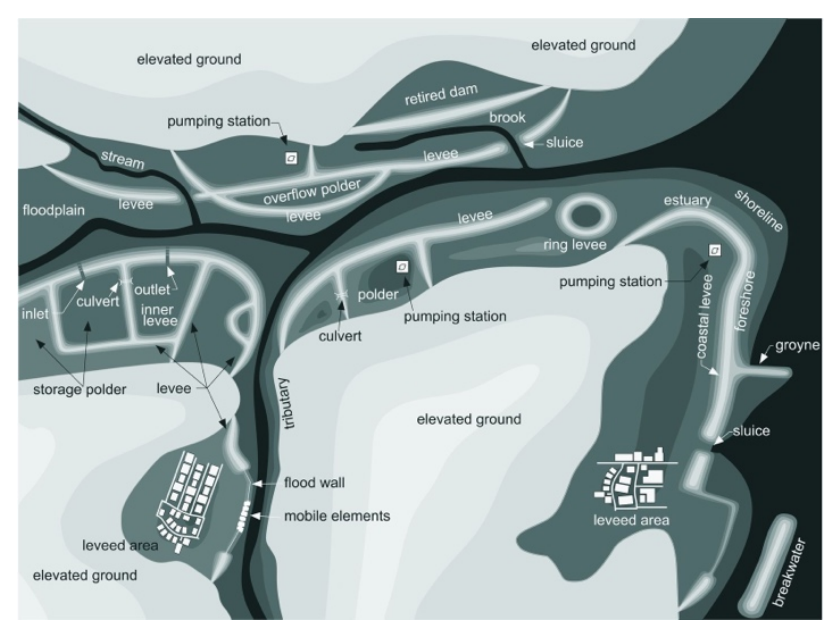

Figure 4. Schematic representation of a coastal flood protection system (Courtesy : Reinhard Pohl)

\section{Potential methodological developments}

The restriction of the study subject to relatively static physical objects such as those constituting protection systems allows their definition by a geographical approach based on cartographic plots (which would not be the case if other vulnerable aspects, including humans, were included in the study). However, the definition of protection systems is not simple: the external contours of the system, as well as the delimitation of the subsets constituting the systems (in general, hydraulic cells) remain potentially variable. For example, in the case of marine flood protection systems, the system limits may vary depending on the physical phenomena that are considered, and their intensity. Thus, the methodology to understand the system behaviour proposed following the analysis of the response to the Xynthia storm [11, 12] provides a procedure for defining a system during an unexpected marine weather event. However, an adaptation of the system or the occurrence of an event with different characteristics, or the evolution of the environment or of the stakes exposure would be valid reasons to revise the definition of the system. In the future, the objective of strengthening the resilience of systems could therefore involve methodological recommendations offering more adaptability in the definition of protection systems.

\subsection{Methods of preservation, restoration or improvement}

The literature abounds with guides and articles providing general or particular insights into the actions to be carried out throughout structure life cycles (from design to decommissioning, through multiple maintenance, restoration or adaptation operations). The International Levee Handbook [6] is a good compendium of the state of the art in this field. However, a single guide cannot address all circumstances. In fact, the coastlines, rivers and torrents - and more specifically estuaries, deltas, lakes and lagoons - have strong singularities. In addition, each region develops its own protection techniques, depending on the hazards and stakes involved, and the resources at its disposal:

- the material resources (soil, sand, rock, concrete, steel, wood, etc.) that depend heavily on the geological context and infrastructure to transport them; and

- the material and financial resources that depend strongly on the economic situation.

For example, after Xynthia, with the primary objective of supporting the restoration of the performance of coastal flood protection systems and adapting these systems in anticipation of future events, methodological frameworks for these coastal territories have been developed to help:

- emergency response preparation, both in terms of general organization (strategy, preparation, training) and specific operations (materials, training and exercises, monitoring, interventions on structures) [5];

- the long-term definition of management and adaptation strategies, including the investment and maintenance costs of the various modes of intervention on levees and other civil engineering works (such as seawalls, groynes, breakwaters, etc.), as well as on beaches and dunes [13];

- the supply of materials guaranteeing the safety of the works, and whose production, transportation, and implementation also respect the principles of reasonable resource management and reduction of greenhouse gas emissions [16];

- the consideration of the hydro-sedimentary functioning of the shoreline [2].

In this example, some issues go well beyond the scope of protection systems:

- additional analyses may be necessary, not at the scale of protection systems, but at the scale of 
sedimentary cells for coastal zones with significant morphological changes; and

- the supply of materials constituting strategic resources and more broadly the mobilization of the means of intervention (personnel, equipment, etc.) may require taking into account simultaneously several potentially affected protection systems, or even very different activities involving the same resources (for example port works).

\section{Potential methodological developments}

Depending on the case study and the proposed actions, the spatial scales of the analysis may be unique or multiple (country, region, protection system, structure), and the disciplines applied should also be clearly identified. Regarding this last point, before the Xynthia storm, the recommendations for the design, adaptation, maintenance, and management of coastal works did not address the economic aspects explicitly enough, since they did not provide assistance in assessing their overall cost. However, at the scale of protection structures, and a fortiori at the scale of a levee system, without economic analyses, it is not possible to evaluate quantitatively the structure life cycle and the long-term project management.

In the future, the objective of strengthening the resilience of protection systems could therefore involve some adjustments to the methodological recommendations relating to the definition of conservation, restoration, or improvement actions. The first step would be to mobilize more disciplines: both engineering sciences, such as hydraulics and geotechnics, to understand the physical behaviour of works, but also geography, history and economics to put into perspective, in space and time, the functional objectives of these works. This requires exploring interactions between these disciplines, as well as between the various actors involved in the decision-making or implementation of operational actions, and producing specific recommendations about this subject.

\subsection{Conclusions of sectoral methodological developments}

Methodological recommendations should support reaching the objectives set out in the definition of resilience, namely the preservation, restoration or improvement of the essential structures and functions of protection systems. In practice, the methodological recommendations are mainly defined by considering only one type of hazard, according to a segmented «sourcepathway-receptor-consequence » approach [9], resulting in successive treatment of :

- the hazard;

- the behavior of the system subject to this hazard; and

- the reaction of the vulnérable stakes to the residual risk.
The plurality of hazards and the interdependent relationships at the level of the protection system and at the level of the elements within the system require complementary approaches. Depending on the various environmental, economic, or social developments, redefining the extent and structures of a system should be considered more frequently. In this sense, the design of systems must already provide for more adaptability.

The study of resilience development strategies also encourages us to pay more attention to the issue of resources, including material, technical, financial, or intellectual resources within the range of utilized disciplines.

Ultimately, integrating the principles associated with resilience requires two actions:

- expanding the approaches used for hazard characterization, the definition of the protection system, and the development of intervention strategies;

- a de-compartmentalization of methodologies, both in the way they are developed and in the way they are applied.

\section{SEEKING UNITY AND CONSISTENCY}

The development of a methodological approach promoting the development of the protection system resilience involves going beyond the framework of sectoral approaches. This finding leads to examining the extent to which the fundamental objectives assigned to methodologies are compatible with the "new principles" stemming from the concept of resilience, where the ecological transition and digital revolution also impose their own rules. This reflection leads to formulating recommendations for the adaptation of methodologies and, as a corollary, for the adaptation (necessary for the effective implementation of methodologies) of leadership, expertise, and planning modes.

\subsection{Fundamental methodological objectives}

Since methodological developments are primarily designed to improve decision-making on the ground, they must reconcile four fundamental objectives:

- contributing to protection system quality control through continuous improvements;

- integrating site-specific characteristics;

- providing time indications for actions;

- accelerating decision making.

\section{Contributing to continuous system improvement}

The management and adaptation of levee systems must be consistent with continuous improvement. The proposed methodologies must assist the stakeholders in this process, by both: 
- encouraging site-specific actions ; and

- capitalizing on experiences from multiple sites for the benefit of others (through the production of guides, but also by highlighting exemplary territories).

Methodological developments and progress on the ground must therefore be mutually enriching. The development of the methodological framework must itself be part of a process of continuous improvement. According to these principles, after the Xynthia storm impacted a multitude of sites, the methodologies previously presented benefited from the observation of the projects in progress.

\section{Integrating site-specific characteristics}

Methodologies are designed to help each actor in charge in the field to define actions that take into account both the characteristics of the environment, as well as the level of expertise and the material and financial resources available. This subject has already been discussed at length in this article, by dealing successively with the characterization of hazards, and the definition of systems and actions. As an illustration, four months after the Xynthia storm, the Minister of State, Jean-Louis Borloo, emphasized the imperative need to respect the sitespecific characteristics by stating:

"In this period of trauma, using the same words, the same process and the same calendar for two significantly different geographic situations was probably an error. I think that's where most of our challenges come from." [15].

\section{Providing time indications for action}

Methodologies should help to plan the timing of diverse actions and to take into account specific circumstances to optimize the overall efficiency and effectiveness. Methodological recommendations should therefore include indications as to when analyses or actions should be carried out. In particular, this information should be provided for the establishment of diagnoses, the revision of flood response plans, and the definition of adaptation projects (in particular by integrating an economic component for calculating the overall cost). References to the life cycles of structures are particularly useful in this regard.

\section{Accelerating decision making}

As responsiveness is an essential parameter for ensuring protective functions, methodologies should assist in accelerating decision-making, while ensuring that the decisions taken remain relevant. This is achieved by shedding light on the appropriate concepts, exposing the necessary knowledge, and providing recommendations for observation and analysis techniques.

\subsection{Adapting methodologies to the concept of resilience}

In the previous section, the fundamental objectives of the methodologies largely overlap with those of resilience since they emerge from the definition of the IPCC: The integration of the specificity of the sites, the provision of time indications and the acceleration of decision-making are reflected in the need to act « in a timely and efficient manner ». In addition, in flood protection, continuous improvement, advocated by the methodological process, can be achieved in the development of this capacity to « anticipate, absorb, accommodate, or recover». It therefore appears that methodological objectives are closely linked to the development of capacities that characterize resilience. This proximity is so great that it could even be assumed that methodological developments, through the capitalization of knowledge and the resources they offer in the preparation of actions, are intrinsically (i.e., regardless of the development of the resilience concept) the first step in resilience development.

More generally, in the history of flood risk management, methodologies have adapted well to the emergence of new concepts that have been a kind of fuel to move them forward. Thus, in flood risk management, the principles of analysis based on the lifecycle of the structures, their failure modes and organization in protection systems, and the "source - pathway - receptor - consequence" model have led to real progress... The emergence of the concept of resilience, by suddenly opening up a range of additional modes of analysis provides a good opportunity to redefine a more relevant framework. The difficulties in adapting the methodological corpus are therefore probably not so much due to the appearance of this new concept as to the major changes in the period when it appeared: the effects of climate change, the ecological transition and the information technology revolution. Therefore, it is necessary, first, to achieve the "fundamental objectives of methodologies" set out above and, second, more broadly, to respect the principles of resilience in an evolving context.

\subsection{Adaptation of methodologies to global changes}

Since methodologies evolve in parallel with actions carried out in the field and over time with feedback, they must have virtually the same qualities as protection systems, particularly with regard to global changes. By using the list of qualities developed for the evaluation of indices in the approach of [1], one seeks to attribute these qualities to the methodologies such that they themselves become integrated, inclusive, reflective, resourceful, robust, flexible and even, when necessary, redundant.

Considering the digital revolution on one hand and environmental disturbances on the other, the possibilities offered by new information technologies can help to adapt to current and future changes (by ensuring naturally that these technologies are used in an environmentally friendly manner) including: 
- the necessary adaptation of information management; and

- the development of tools that can be used in all circumstances.

\section{Adaptation of information management}

The management of flood protection systems involves, in crisis situations and in restoration or adaptation phases, decisions based on numerous and heterogeneous data. This leads to various and potentially highly elaborate information processing. In addition, the requirements of risk protection and environmental preservation, both of which are enshrined in laws and regulations, can give decision-makers, particularly in crisis situations, the impression of being subject to contradictory injunctions. Stakeholder interests that may also result in opposition and slowdowns or blockages may occur. Consequently, decision-making often takes longer, if not much longer, than the implementation of the measures.

In analyzing this situation in a pragmatic way, it appears that climate change and the ecological transition require more data to be taken into account in management and adaptation actions: not only those related to risk management, but also those associated with the preservation of the environment. The digital transition also means that we have more and more data (characterization of meteorological and hydrodynamic phenomena, condition and behavior of structures, characterization of strategic materials resources, etc.). Observational tools have progressed and generate this mass of information. In parallel, analysis tools often exploit this information through models or geographic information systems. This way of understanding reality can be extremely effective in describing the functioning of protection systems, in predicting their behavior and in organizing operational interventions. Nevertheless, the data must be accessible and organized in such a way that the mass of information does not become paralyzing for decision-making. Otherwise, the risk of being drowned in the information flow is not only virtual: the consequences can be very real.

With regard to the fundamental objectives of the methodologies, the development of information technology can improve taking into account the sitespecific characteristics. Modelling and geolocation tools can contribute to the continuous improvement of the protection system by integrating more data in time. However, the use of high-tech tools exploiting a large amount of information can undermine the objective of accelerating decision-making if decision-making patterns are not adapted to this technological environment.

A necessary condition for achieving the fundamental objectives of the methodologies is to design databases that are adapted to the developed methodologies (and vice versa). Adaptation to the effects of climate change and other environmental disturbances certainly requires an ability to make this combination of databases and methodologies evolve and to supplement the databases at a frequency sufficient to monitor developments. This can be done, for example, by updating the cost study of coastal protection [3], the Inventory of armourstone [4], or flood response plans.

\section{Development of tools that can be used in all circumstances}

The regulatory framework requires the establishment of emergency response plans to deal with crisis situations and to restore the normal functioning of the protection system... These emergency plans define the operational organization of the response and technical arrangements as well as the staff preparedness to deal with degraded situations. These plans are naturally an essential part of crisis management. Although it is necessary to provide an emergency management system that is distinct from the normal one, certain methodological developments designed for these two situations would often benefit from being considered as a whole. In particular:

- economic studies should consider the entire life cycle of the project to optimize the overall cost and the expected service throughout the period considered. Note that this analysis goes beyond the strict framework of the protection system: the optimum overall cost (according to different hypotheses) can be defined only by a costbenefit analysis of the whole system and the stakes it protects;

- methodological frameworks for the diagnosis of systems should encourage the installation of devices for observing their behavior in crisis situations;

- the methodological framework for project management should include provisions facilitating emergency repairs;

- the methodological framework for the supply of materials should anticipate the stresses resulting from crisis situations.

This global approach is all the more justified since constant changes in levee systems under the influence of multiple natural and anthropogenic actions should never be neglected: management strategies in normal time (resistance to slow disturbances) should accompany crisis management strategies (resistance to shocks). Within this framework, nature-based solutions often appear to be the most relevant to build resilience, while limiting expenses and environmental impacts.

If current and future changes require making additional efforts to define adaptation strategies, it is necessary to continue monitoring the structures and to ensure that their performance is maintained... It appears that these two aspects should never be dissociated because the resilience of systems can also be enhanced by strengthening the links between them, particularly in the establishment of the decision- 
making. The methodologies should be defined in accordance with this principle. The production of the International Levee Handbook [6], covering all these topics, has fostered synergies. This effort should be maintained in future developments.

\subsection{Adaptation of governance, expertise and planning modes}

By analogy with the development of the methodological corpus, the concept of resilience is an aid in defining the modes of governance, expertise and planning to address the constraints imposed by global changes.

\section{Adaptation of governance modes}

By looking at the evolution of governance modes relative to flood risk protection in France, it is particularly clear that:

- Decree 2015-1826 of 12 May 2015 (levee Decree), basing the authorizations on the concept of «levee system » and not on isolated levees, marked a turning point in the management of flood risk. This new framework required a single manager per levee system and the production of a specific hazard study for the system;

- Law No. 2014-58 of 27 January 2014, giving municipalities a targeted and compulsory power on the management of aquatic environments and flood prevention gave them the means to jointly address the problems of «water security » and « environmental protection».

Concerning this last subject, it should be noted that the power is given to public institutions for intercommunal cooperation with a proper tax system. This means that the manager is able to mobilize funds to carry out all the actions accompanying the lifecycle of the structures. A levee system with no financial resources would have very little or no resilience. Identifying managers with the capacity to raise funds is therefore crucial to strengthening the resilience of the system.

Through this example, it is clear that methodological developments would be useless without legislative and regulatory support, and without legitimate institutions to raise funds and design and implement action programs.

\section{Adaptation of expertise and development modes}

An essential mission of expertise is to guide the development of protective systems towards resilient solutions. One criterion is that these developments facilitate decision-making. There are two ways to do this:

- the project is designed in such a way that it manages itself: the adoption of nature-based solutions meets this criterion; or

- the project has characteristics that make it possible to manage it serenely: well identified and available means, sustainable exploitation of resources...

Resilience-building approaches can also be beneficial in mitigating the effects of slow disturbances. For example, designing robust and redundant levee systems will give more time to react to degradation of levees that may be generated by tree roots or burrowing animals. This type of design will allow levee managers to take a more serene stance in comparison to a design that is dimensioned to optimize performance relative to a single reference event.

The utilization of several disciplines in the development of methodologies is also a means that is difficult to substitute when it comes to forge links between the actors involved in expertise activities. Similarly, if a material recovery stream is created, the links between the stakeholders in that stream will improve crisis management.

\subsection{Findings on the search for unity and consistency}

In conclusion, it appears that methodological production relating to the links between resilience and protective works is an activity whose intrinsic characteristics can improve the management of the structures with a richer and more integrative approach. In an age marked by profound changes in the environment and by a technological revolution, methodological production has become essential for the societal adaptation, provided that it encourages the utilization of various disciplines and strengthens the solidarity between the different actors. The links between disciplines and actors must be woven over time, under normal circumstances, in order to be able to be applied rapidly in crisis situations. Urban Engineering, « set of disciplines to enable life in urban areas ", is likely to meet this need for multidisciplinarity: urban engineering is indeed based on a holistic vision of complex realities in reaction to the analytical approach of its component techniques.

Finally, it should be noted that progress in the field of applied research does not trigger automatically effective application in the field. It is therefore essential to carry out actions to disseminate knowledge and to take ownership of the developed methodologies. Governance arrangements can also be revised to encourage increasing the expertise shared with levee managers.

\section{Conclusion}

History has largely shown that levee systems cannot protect a site against any type of event, if only because of changes in the environment and limited financial and material resources. Their rapid restoration is a prerequisite for the restoration of normal living conditions within the levee system. Adapting the system to the uncertain conditions created by climate change is 
another challenge for levee managers. Methodological developments, coupled with actions to disseminate knowledge, represent an essential pathway to strengthen the resilience of systems, a concept that integrates both recovery and adaptation capacity.

Methodological developments in hazard knowledge, protection system definition, and interventions on structures must continue. Nevertheless, it seems possible in a search for unity and coherence, to adopt a more transversal approach, because these methodological developments are based on the same principles and their implementation draws on the same data sources. Methodological development programs will therefore always require real coordination to respond optimally, in the short, medium or long term, to developments, whether global (linked for example to climate change) or more local (related for example to land use).

In recent years, changes in governance modes and in project options have led, more than in the past, to considering jointly the issues of protection against risks and preservation of the natural environment. These developments are very positive for building resilience over the long term.

Ultimately, the development of methodologies and operational tools must be designed to serve in all circumstances, within the framework of a global, integrated and cohesive approach.

\section{References}

1. Arup and the Rockefeller Foundation (2018). City Resilience Index Brochure. URL: https://www.cityresilienceindex.org/\#/resources (visited on 02/2020).

2. Cerema (2015). Analyse du fonctionnement hydro-sédimentaire du littoral - Cahier technique.

3. Cerema (2016). Coût des protections contre les aléas littoraux

4. Cerema (2016). Atlas des carrières d'enrochements

5. Cerema (2018). Interventions d'urgence sur les dispositifs de protection contre les submersions marines.

6. CIRIA, MEDDE, USACE (2013). The International Levee Handbook. CIRIA, C731.

7. Dicophilo, dictionnaire philosophique en ligne. URL : https://dicophilo.fr/definition/systeme/ (visited on 03/2020).

8. Disse M. et al. (2020). Exploring the relation between flood risk management and flood resilience. Water Security. Volume 9, 100059

9. Gouldby B., Samuels P. et al. (2005). Language of Risk - Project definitions. FLOODsite Report T32-04-01. http://www.floodsite.net

10. de Graaf R., van de Giesen N., et al. (2009), Alternative water management options to reduce vulnerability for climate change in the Netherlands, Natural Hazards 51: 407-422
11. Igigabel M. et al (2016). Coastal flood protection systems. Xynthia feedback experience. Case studies conclusion. Revue Paralia. Volume 9. s04.1-s04.6

12. Igigabel M. et al (2016). Coastal flood protection systems - concepts and analysis. 3rd European Conference on Flood Risk Management, E3S Web of Conferences. Volume 7, paper 03011

13. Igigabel M., Yates M. (2018). Cost study of coastal protection. Proceedings of the Coastal Engineering Conference, 1(36), papers.87.

14. IPCC. Managing the Risks of Extreme Events and Disasters to Advance Climate Change Adaptation. Special Report of the Intergovernmental Panel on Climate Change. Cambridge, England: Cambridge University Press, 2012.

15. Leonard J.-L. (2010). Rapport d'information n²697 à l'Assemblée nationale sur les raisons des dégâts provoqués par la tempête Xynthia

16. Le Turdu V., M. Igigabel et al (2016). Inventory of armourstone. 3rd European Conference on Flood Risk Management (FLOODrisk 2016), E3S Web of Conferences. Volume 7, paper 12006

17. Mazas F., Kergadallan X. et al. (2014). Applying POT methods to the Revised Joint Probability Method for determining extreme sea levels. Coastal Engineering, 91 : 140-150 